\title{
Detection and Dietary Exposure Assessment of Fluoroquinolones Residues in Chicken Meat from the Districts of Malang and Blitar, Indonesia
}

\author{
R. Widiastuti*, E. Martindah, \& Y. Anastasia \\ Indonesian Research Center for Veterinary Science \\ Jalan RE Martadinata 30, Bogor 16114, Indonesia \\ *Corresponding author: widiastuti.raphaella@gmail.com \\ (Received 05-04-2021; Revised 08-06-2021; Accepted 27-07-2021)
}

\begin{abstract}
The purpose of this study was to determine the presence of fluoroquinolones (enrofloxacin and ciprofloxacin) residues in fresh chicken meat and evaluate its consumption risk to the adult population in Indonesia. A total of 55 fresh chicken-meat samples were collected from Districts of Malang and Blitar, East Java Province, Indonesia, in April 2017. Detections of enrofloxacin and ciprofloxacin were carried out using high-performance liquid chromatography equipped with a PDA detector. It was found that ciprofloxacin was detected with a frequency of $67.3 \%$ at a maximum concentration of $275.00 \mathrm{ng} / \mathrm{g}$. Enrofloxacin was detected with a frequency of $41.8 \%$ at a maximum concentration of $242.40 \mathrm{ng} / \mathrm{g}$, or totally as a sum of enrofloxacin and ciprofloxacin residues detected in $76.4 \%$ samples at a maximum concentration of $367.50 \mathrm{ng} / \mathrm{g}$. The estimated dietary intakes of ciprofloxacin and enrofloxacin were $44.90 \mathrm{ng} / \mathrm{kg}$ body weight/day and $7.91 \mathrm{ng} / \mathrm{kg}$ body weight/day, respectively, resulting in the hazard indexes of 0.0063 and 0.0013 for the consumptions of ciprofloxacin and enrofloxacin residues in chicken meat. Therefore, the risk associated with the consumption of ciprofloxacin and enrofloxacin residues in chicken meat by the adult population in Indonesia was considered negligible.
\end{abstract}

Keywords: Ciprofloxacin residue; enrofloxacin residue; chicken meat; HPLC; dietary exposure assessment

\section{INTRODUCTION}

Chicken meat is the most popular source of protein in Indonesia. It has emerged as a good substitute for beef. However, the infectious diseases and subsequently indiscriminate drug usage, without observing the withdrawal period, have made the poultry products unsafe for human health due to antibiotic residues. Fluoroquinolones such as ciprofloxacin, enrofloxacin, and nalidixic acid, have been widely used for treatment and pre/post-exposure prophylaxis in poultry farms (Er et al., 2013).

Fluoroquinolones are powerful options among the antimicrobial agents used for curing bacterialcaused poultry diseases (Trouchon \& Lefebvre, 2016). Enrofloxacin has antibacterial activity against Enterobacteriaceae, Gram-negative bacteria, and some Gram-positive cocci (Gouvêa et al., 2015). This drug is widely used in the treatment of poultry for mycoplasma, colibacillosis, and Pasteurella's infections (Šandor et al., 2012). Meanwhile, ciprofloxacin is effective for microorganisms resistant to aminoglycosides, tetracycline's, macrolides, and $\beta$-lactams (Sultan, 2014). The recommended dose of enrofloxacin in poultry is 10 $\mathrm{mg} / \mathrm{kg}$ body weight for 3 to 5 days of treatment (EMEA, 1998).
Enrofloxacin is metabolized into ciprofloxacin in most species. However, as residues, both enrofloxacin and ciprofloxacin are heat-stable compounds (Hasanen et al. 2016) and thus represent a serious health concern. Some countries (see Table 1) had established the maximum residue limit (MRL) of enrofloxacin, calculated as the sum of enrofloxacin and ciprofloxacin.

To analyze the presences of ciprofloxacin and enrofloxacin residues in meat can be detected with the use of high-performance liquid chromatography (HPLC) equipped with a fluorescence detector, UV detector (Cañada-Cañada et al., 2012), diode array detector (Oyedeji et al., 2019), or LC-MS/MS (Thi Huong-Anh et al., 2020). However, no reports have been published on detecting fluoroquinolones residues in chicken meat in Indonesia for the last ten years. This study aimed to determine the presence of enrofloxacin and its metabolite (ciprofloxacin) residues in chicken meat collected in Malang and Blitar Districts in East Java Province and to perform the risk assessment of consumption of enrofloxacin and ciprofloxacin residues in chicken meat to the adult population in Indonesia by calculating the estimated daily intake (EDI) and by comparing the values found with the acceptable daily intake (ADI). 
Table 1. The maximum residue limit (MRL)s of enrofloxacin (sum of ciprofloxacin + enrofloxacin) established in several countries

\begin{tabular}{|c|c|c|c|c|c|c|}
\hline \multirow{2}{*}{ Tissue } & \multicolumn{6}{|c|}{ MRLs of enrofloxacin (ng/g) } \\
\hline & Indonesia $^{1}$ & USA $^{2}$ & European Union ${ }^{2}$ & Japan $^{2}$ & Taiwan $^{3}$ & India $^{4}$ \\
\hline Muscle & 10 & banned & 100 & 10 & 100 & NE \\
\hline Liver & NE & banned & 200 & 10 & 300 & NE \\
\hline
\end{tabular}

Note: NE= not established. ${ }^{1}=$ adopted from BSN (2000); ${ }^{2}=$ adopted from Sureshkumar \& Sarathchandra (2018); ${ }^{3}=$ adopted from Tsai $e t$ al. $(2019) ;{ }^{4}=$ adopted from Vishnuraj et al. (2016).

\section{MATERIALS AND METHODS}

\section{Sample Collection}

The research protocol was evaluated and approved by the Institution Review Board for Animal Care and Ethics Committee at the Indonesian Research Center for Veterinary Science, Bogor (Balitbangtan/ Balitvet/A/06/2017).

A total of 55 breast samples of chicken ready to be marketed (ages of 28-32 days) were collected randomly from 28 small and medium scale chicken broiler farms in April 2017 in the Districts of Malang (21 farms, n= 42 samples) and Blitar (7 farms, $\mathrm{n}=13$ samples), East Java Province, Indonesia. At approximately $200 \mathrm{~g}$ of meat was cut aseptically from the breast and transported to the laboratory under cold condition in a foam box containing chiller packs. All the meat samples were stored at $-20{ }^{\circ} \mathrm{C}$ until the time of analysis.

\section{Chemicals, Reagents, and Solutions}

All reagents and solvents were of analytical or HPLC grade quality and supplied by Merck (Darmstadt, Germany). Ultrapure water was generated by a water purification system Milli Q Direct 8/16 System (Millipore SAS, 67120 Molsheim, France). All standards were of high purity grade $(>90 \%)$ and were supplied by Vetranal (Sigma-Aldrich, Darmstadt, Germany). The quality of reagents and standard solutions was of analytical grade.

\section{Residue Determination in Chicken Meat Samples}

The extraction method was adopted from Ovando et al. (2004) with minor modifications. Minced chicken meat was weighed $(0.2 \pm 0.02 \mathrm{~g})$ and placed into a
$15 \mathrm{~mL}$ glass tube. Phosphate buffer $(2 \mathrm{~mL})$ was used to homogenize the sample. Dichloromethane $(8 \mathrm{~mL})$ was added and vortexed to the homogenate for $1 \mathrm{~min}$ before centrifuging at $4000 \mathrm{rpm}$ for $20 \mathrm{~min}$. The upper aqueous layer was discarded, the organic phase was separated to a clean tube, and the tissue was reextracted with the addition of dichloromethane $(6 \mathrm{~mL})$. The combined organic layers evaporated at $30{ }^{\circ} \mathrm{C}$ under a nitrogen stream. The extract was re-dissolved with $500 \mu \mathrm{L}$ of the mobile phase, filtered through a $0.45 \mu \mathrm{m}$ PVDF syringe filter unit before being injected into the HPLC. Chromatographic separation was carried out on Shimadzu LC20AD HPLC (Shimadzu, Kyoto, Japan) with a $\mathrm{C}_{18}$ Sunfire column ( $5 \mu \mathrm{m} ; 4.6 \times 250 \mathrm{~mm}$ ) (Waters, (Ireland) and detected with the SPD-M20A photodiode array (PDA) detector at $277 \mathrm{~nm}$. The mobile phase of a mixed $0.2 \mathrm{M}$ trichloroacetic acid (TCA)-methanolacetonitrile (74:4:22) was filtered through a $0.45 \mu \mathrm{m}$ PVDF filter (Whatman, Maidstone, UK) before being used and run isocratic at a flow rate of $1.0 \mathrm{~mL} / \mathrm{min}$. The volume of the residue injected manually into the HPLC was $20 \mu \mathrm{L}$.

\section{Method Performance}

The chromatogram of separation for ciprofloxacin $(\mathrm{CPF})$ and enrofloxacin (ENR) from the matrix shown in Figure 1, having retention times of 6.6 minutes and 8.7 minutes, respectively. Validation parameters were partially conducted in terms of linearity, recovery, inter-day precision (\% RSD), the limit of detection (LOD), and the limit of quantification (LOQ). To evaluate the linearity of the method for different samples, five points matrixmatched calibration curves were obtained through spiking different blank samples with ciprofloxacin and enrofloxacin in the concentration range of $7-100 \mathrm{ng} / \mathrm{g}$, and the analytical curves gave the correlation coefficient $\left(R^{2}\right)$

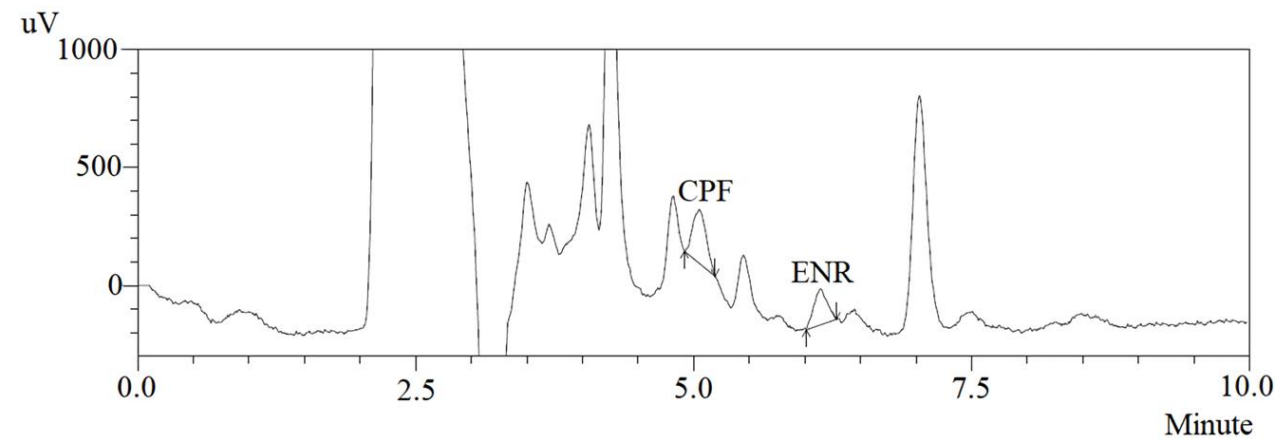

Figure 1. Chromatogram of ciprofloxacin (CPF) and enrofloxacin (ENR) separation in a positive residue sample 
of 0.9994 and 0.9993 , respectively. The method's repeatability was evaluated by extracting and analyzing $50 \mathrm{ng} /$ $\mathrm{mL}$ standard solutions of ciprofloxacin and enrofloxacin six times $(n=6)$ to generate a relative standard deviation (RSD) $0.13 \%$ and $0.11 \%$, respectively. The method recoveries were conducted by spiking blank samples with ciprofloxacin and enrofloxacin in triplicate at the levels of 10,50 , and $100 \mathrm{ng} / \mathrm{g}$ and calculated the percentage of the experimentally derived concentration to the nominal concentration, and resulted in the recoveries of $86.39 \%$ and $99.74 \%$, respectively. The limit of detection (LOD) was a signal value of three times the noise, and the limit of quantification (LOQ) was ten times the noise. The LOD obtained for ciprofloxacin and enrofloxacin were $4.21 \mathrm{ng} / \mathrm{g}$ and $3.49 \mathrm{ng} / \mathrm{g}$, respectively. Meanwhile, the LOQ for ciprofloxacin and enrofloxacin were 9.06 and $7.67 \mathrm{ng} / \mathrm{g}$, respectively. The validation parameters of enrofloxacin and ciprofloxacin detection in chicken meat samples are summarized in Table 2 and are following the European Commission Decision 2002/657/EC 2002 (EC, 2002).

\section{Risk Assessment of Dietary Exposure of Fluoroquinolones Residues}

The estimated daily intake (EDI) of the antibiotic residue was calculated to assess the extent to which people had been exposed to its residues in chicken meat. The acceptable daily intakes (ADIs) established by the World Health Organization (WHO) and the Food and Agriculture Organization of the United Nations (FAO),

Table 2. Validation parameters of enrofloxacin and ciprofloxacin detection in chicken meat samples

\begin{tabular}{lcc}
\hline \multicolumn{1}{c}{ Parameters } & Ciprofloxacin & Enrofloxacin \\
\hline Linearity Range (ng/g) & $7-100$ & $7-100$ \\
Precision (RSD) (\%) & 0.13 & 0.11 \\
Correlation coefficient ( $\mathrm{r}^{2}$ ) & 0.999 & 0.999 \\
Recovery (\%) & 86.39 & 99.74 \\
Limit of detection (LOD) (ng/g) & 4.21 & 3.49 \\
$\begin{array}{l}\text { Limit of quantification (LOQ) } \\
\text { (ng/g) }\end{array}$ & 9.06 & 7.67 \\
\hline
\end{tabular}

namely $7.1 \mu \mathrm{g} / \mathrm{kg}$ body weight/day for ciprofloxacin and $6.2 \mu \mathrm{g} / \mathrm{kg}$ body weight/day for enrofloxacin (Hana et al., 2018), were employed as points of comparison. The following equation was used to calculate the EDI (Moudgil et al., 2019) as follows:

$\operatorname{EDI}\left(\frac{\mathrm{ng} / \mathrm{kg} \text { body weight }}{\text { day }}\right)=\frac{\left.\text { (Mean veterinary drug concentration }\left[\frac{\mathrm{ng}}{\mathrm{g}}\right] \times \text { Daily intake of food }\left[\frac{\mathrm{g}}{\mathrm{day}}\right]\right)}{\text { Human body weight }(\mathrm{kg} \text { body weight) }}$

The mean concentrations of fluoroquinolones were derived from all samples (including samples with detected and undetected concentrations). Data regarding Indonesian citizens' daily chicken meat consumption ( 29.0 g/day), consumed by $21.5 \%$ of Indonesian people, which was adopted from "Diet total study: Survey of individual food consumption Indonesia 2014" was released by the Indonesian Ministry of Health (Siswanto, 2014). The mean body weight of Indonesian adults is considered to be $60 \mathrm{~kg}$.

The hazard index $(\mathrm{HI})$ is the ratio of EDI to ADI (HI $=\mathrm{EDI} / \mathrm{ADI}$ ) to estimate the potential health risk for each antibiotic. When the $\mathrm{HI}$ is less than $1(\mathrm{HI}<1)$, there is no risk associated with the consumption of poultry products. However, when $1 \leq \mathrm{HI} \leq 10$ indicates that risk exists, but does not require immediate action, while when $\mathrm{HI}>$ 10, it shows that the risk is unacceptable (Oyedeji et al., 2019).

\section{RESULTS}

\section{The Presence of Fluoroquinolones Residues in Chicken Meat Samples}

The incidence and concentration levels of fluoroquinolones residue in a total of 55 chicken meat samples are shown in Figure 2 and Table 3. It was found that ciprofloxacin occurred with a detection frequency of $67.3 \%$ with a maximum concentration of $275.00 \mathrm{ng} / \mathrm{g}$ and the mean concentration of $91.22 \pm 70.49 \mathrm{ng} / \mathrm{g}$. In contrast, enrofloxacin occurred with a detection frequency of $41.8 \%$ with a maximum concentration of $242.50 \mathrm{ng} / \mathrm{g}$ and the mean concentration of $16.36 \pm 47.98 \mathrm{ng} / \mathrm{g}$, or totally as a sum of enrofloxacin and ciprofloxacin residue was detected in $76.4 \%$ of samples with the maximum concentration of $367.50 \mathrm{ng} / \mathrm{g}$ and the mean concentration

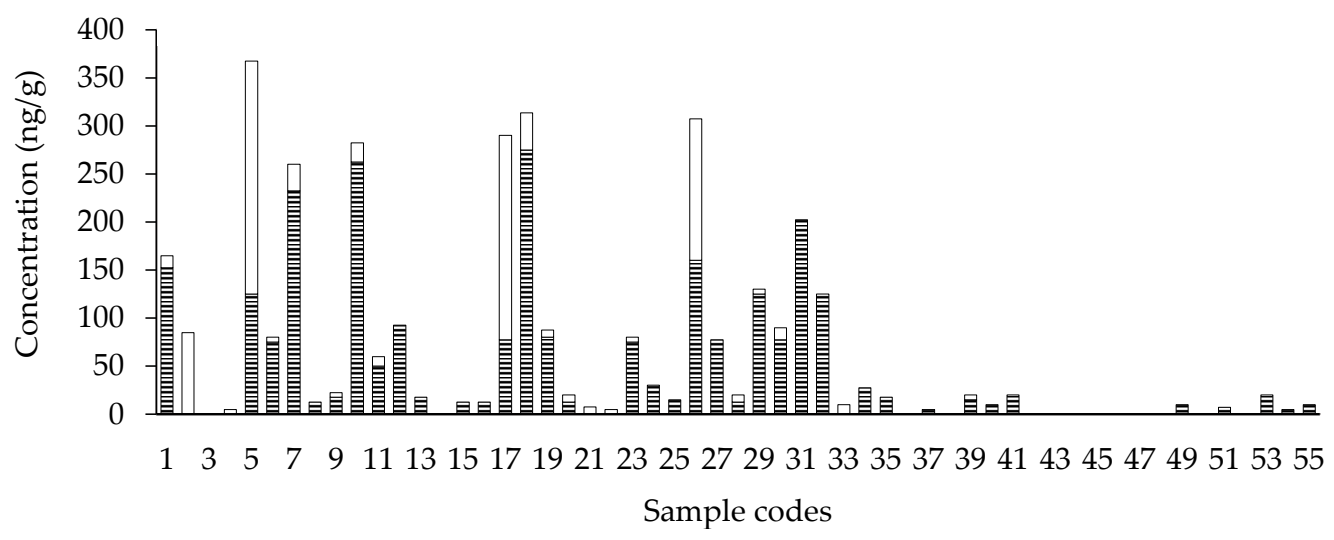

Figure 2. Residue concentrations of ciprofloxacin and enrofloxacin in 55 chicken meat samples from Districts of Malang (sample codes: 1-42) and Blitar (sample codes: 43-55), East Java Province. ( $\square=$ Enrofloxacin). 
Table 3. Detection incidences, ranges, and means concentration of fluoroquinolones in 55 chicken meat samples

\begin{tabular}{lccc}
\hline \multicolumn{1}{c}{ Fluoroquinolones } & Incidence $(\mathrm{n}, \%)$ & Range $(\mathrm{ng} / \mathrm{g})$ & Mean \pm SD $(\mathrm{ng} / \mathrm{g})$ \\
\hline Ciprofloxacin (CPF) & $\mathrm{n}=37(67.3 \%)$ & $5.0-275.0$ & $91.22 \pm 70.49$ \\
Enrofloxacin (ENR) & $\mathrm{n}=23(41.8 \%)$ & $5.0-242.5$ & $16.36 \pm 47.98$ \\
Total of CPF + ENR & $\mathrm{n}=42(76.4 \%)$ & $5.0-367.5$ & $66.76 \pm 104.61$ \\
\hline
\end{tabular}

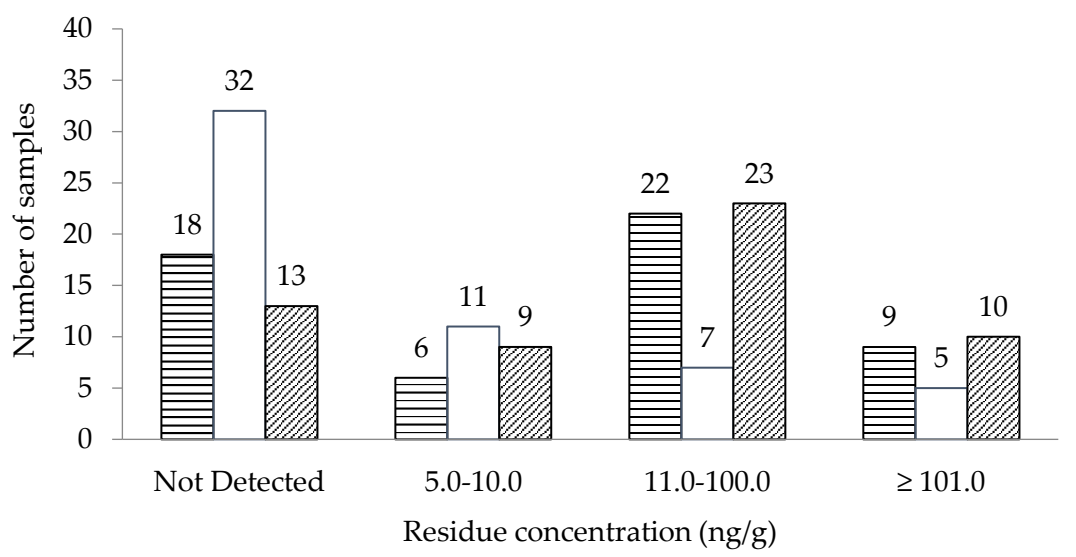

Figure 3. Distributions of fluoroquinolones residue concentrations in 55 chicken meat samples. (E= Ciprofloxacin, $\square$ = Enrofloxacin, and $\mathbb{Z}=$ Total Ciprofloxacin + Enrofloxacin).

of $66.76 \pm 104.61 \mathrm{ng} / \mathrm{g}$. The highest contamination level of fluoroquinolones was found for the sample code of 5 from Malang District (sum of $125.00 \mathrm{ng} / \mathrm{g}$ of ciprofloxacin and $242.50 \mathrm{ng} / \mathrm{g}$ enrofloxacin). The prevalence and the concentration obtained of ciprofloxacin residues were higher than those of enrofloxacin residues.

Figure 3 gives the breakdown results of contamination distribution for ciprofloxacin and enrofloxacin residues. Ciprofloxacin did not contaminate 18 samples but contaminated 6 samples at a concentration range of 5.00 to $10.00 \mathrm{ng} / \mathrm{g}, 22$ samples at a concentration range of 11.00 to $100.00 \mathrm{ng} / \mathrm{g}$, and 9 samples at a concentration above $101.00 \mathrm{ng} / \mathrm{g}$. Meanwhile, enrofloxacin did not contaminate 32 samples but contaminated 11 samples at a concentration range of 5.00 to $10.00 \mathrm{ng} / \mathrm{g}$, seven samples at a concentration range of 11.00 to $100.00 \mathrm{ng} / \mathrm{g}$, and five samples at a concentration above $101.00 \mathrm{ng} / \mathrm{g}$.

\section{Risk Assessment Evaluation}

The health-risk evaluation of the residual fluoroquinolones concentrations was assessed from the estimated daily intakes (EDI) of ciprofloxacin and enrofloxacin residues obtained from chicken meat consumption as well as hazard index (HI) are presented in Table 4 . The calculated EDI of ciprofloxacin and enrofloxacin residues in chicken meat was $44.90 \mathrm{ng} / \mathrm{kg}$ body weight/day and $7.91 \mathrm{ng} / \mathrm{kg}$ body weight/day, and resulted in the HI of 0.0063 and 0.0013 , respectively.

\section{DISCUSSION}

The presence of ciprofloxacin and enrofloxacin residues in samples indicated that farmers in poultry production used those two antibiotics as therapeutic or prophylactic agents or, for some cases, might be caused
Table 4. Estimated dietary intakes (EDI) and hazard indexes (HI) for ciprofloxacin and enrofloxacin residues consumed in chicken meat by Indonesian adults

\begin{tabular}{cccc}
\hline Fluoroquinolones & $\begin{array}{c}\text { EDI }(\mathrm{ng} / \mathrm{kg} \\
\text { BW/day) }\end{array}$ & $\begin{array}{c}\text { ADI }(\mu \mathrm{g} / \mathrm{kg} \\
\text { BW/day) }\end{array}$ & $\begin{array}{c}\mathrm{HI} \\
(\mathrm{EDI} / \mathrm{ADI})\end{array}$ \\
\hline Ciprofloxacin (CPF) & 44.9 & 7.1 & 0.006 \\
Enrofloxacin (ENR) & 7.91 & 6.2 & 0.001 \\
\hline
\end{tabular}

Note: acceptable daily intake (ADI) values adopted from Hanna et al. (2018); BW= body weight.

by the misuse or excessive use. In adherent to withdrawal, the time has resulted in the spread of antibiotics residues (as the parent compound or its metabolite) in chicken meat. Another reason might be because of changes in the chemical structure of enrofloxacin metabolized to ciprofloxacin (Trouchon \& Lefebvre, 2016). The high frequencies and concentrations observed in these studies highlight the possibility of the emergence of bacterial resistance.

Antibiotics, especially in developing countries, are available for livestock use without a prescription, and imported illegal products sometimes lack instructions in the local language (Yamaguchi et al., 2015). Pereira et al. (2018) also indicated that detection of high frequencies and concentrations of fluoroquinolones residues indicated the widespread use of those antibiotics arose from the lack of authorized observation. Additionally, since this study was conducted in 2017, antibiotics were still permitted for seven days of maximum feeding use for therapeutic purposes. The prohibition on antibiotics for growth promoters was stated on the Regulation of The Minister of Agriculture of The Republic of Indonesia Number 14/Permentan/PK.350/5/2017 and implemented since the first of January 2018. 
To avoid residue formation in animal products, the withdrawal time (WDT) and maximum residue limit (MRL) of medications should be defined. Drug residues in animal products are caused by a lack of knowledge about the proper WDT of medications, as well as overuse or misuse of the drugs. By applying the Indonesian MRL of enrofloxacin (10.0 ng/g), there would be 22 $(40 \%)$ samples that were safe and $33(60 \%)$ samples that were not safe to be consumed. Still, if applying the EU's MRL, there would be $45(81.8 \%)$ samples were safe, and only $10(18.2 \%)$ samples were considered unsafe to be consumed. For this reason, it is important to evaluate whether MRL of $10 \mathrm{ng} / \mathrm{g}$ is suitable to be implemented in Indonesia since most worldwide countries established at $100 \mathrm{ng} / \mathrm{g}$, which is more realistic to be applied based on achievability limit on analytical determination for both enrofloxacin and ciprofloxacin using HPLC of mostly above $10 \mathrm{ng} / \mathrm{g}$. San Martin et al. (2010) also suggested that when the lower MRL was considered 10 $\mathrm{ng} / \mathrm{g}$, the WDTs increased up to 8 days, but when the MRL was defined at $100 \mathrm{ng} / \mathrm{g}$, the WDTs did not exceed five days. This means to deliver safe food for human consumption, the WDTs of a drug also relate to the MRL.

Our findings in the presence of ciprofloxacin and enrofloxacin residues in chicken meat closely similar to the results of Marni et al. (2011) from their study in Malaysia that 10 out of 37 samples were contained both ciprofloxacin at a concentration range of 3.42-238.11 $\mathrm{ng} / \mathrm{g}$ and enrofloxacin in 33 samples at a concentration range of 3.51-1,734.61 ng/g. Meanwhile, Er et al. (2013) from Turkey also found that $45.7 \%$ out of 127 samples were positive for quinolones at a mean concentration of $30.81 \mathrm{ng} / \mathrm{g}$ or Mashak et al. (2017) in Iran who found $59.2 \%$ out of 233 chicken meat samples at mean levels of $37.86 \mathrm{ng} / \mathrm{g}$. Aslam et al. (2016) from Pakistan found that $52 \%(39 / 75)$ meat samples were positive for enrofloxacin in the concentration range of $208 \pm 55 \mathrm{ng} / \mathrm{g}$, respectively, and $58.3 \%$ (21) meat samples had a residual concentration above the maximum residual limit of $100 \mathrm{ng} / \mathrm{g}$. Most of those findings revealed that some samples had the residual concentration above the residual limit of $100 \mathrm{ng} / \mathrm{g}$, which were commonly found mostly in the developing countries, which were different from the conditions in the developed countries such as Korea (Lee et al., 2018) or Spain, UK and Portugal (Pereira et al., 2018) where there were no samples containing residues that exceed the MRL. In addition, Pugajeva et al. (2018) also reported high prevalence $(93 \%, n=40)$ of fluoroquinolones residues in poultry meat retails from Estonia, Latvia, Lithuania, Poland, and France at the concentration range of 0.003 to $1.13 \mathrm{ng} / \mathrm{g}$.

The HI values of 0.0063 and 0.0013 for ciprofloxacin and enrofloxacin, was obtained based on the EDI values of $44.90 \mathrm{ng} / \mathrm{kg}$ body weight per day for ciprofloxacin and $7.91 \mathrm{ng} / \mathrm{kg}$ body weight per day for enrofloxacin, respectively. The risk associated with the consumption of poultry products for an adult population in Indonesia is negligible because the $\mathrm{HI}$ for ciprofloxacin and enrofloxacin in all the samples analyzed was less than 1 (HI $<1)$.
Previous studies on the risk exposure of fluoroquinolones in chicken meat from other countries are very scarce. A study conducted in Portugal by Pena et al. (2010) evaluated that the EDI for enrofloxacin in chickens was $0.029 \mathrm{ng} / \mathrm{kg}$ body weight/day. Another study conducted by Pereira et al. (2018) revealed that the highest EDI for the sum of enrofloxacin $(0.46 \mathrm{ng} / \mathrm{kg}$ body weight/day) was acquired for the population of 3-year-olds.

\section{CONCLUSION}

The presence of fluoroquinolones (enrofloxacin and ciprofloxacin) residues in some chicken meat samples from the Districts of Malang and Blitar, East Java Province, indicated that enrofloxacin and/or ciprofloxacin were still used by farmers, namely before the implementation of the prohibition on antibiotic use in Indonesia. Due to very strict regulation on the value of maximum residue level (MRL) in Indonesia $(10 \mathrm{ng} / \mathrm{g}$ of the sample weight), $60 \%$ of samples examined contained enrofloxacin residue above MRL. Based on the EDI followed with the HI calculation, the risk associated with enrofloxacin/ciprofloxacin residue consumption in chicken meat is considered negligible to threaten the human health of the Indonesian adult population.

\section{CONFLICT OF INTEREST}

The authors declare that there are no financial, personal, or other links with any people or organizations mentioned in this manuscript that are related to the subject of the article that could create a conflict of interest.

\section{ACKNOWLEDGEMENT}

We would like to express our gratitude to the Indonesian Agency for Agricultural Research and Development, Ministry of Agriculture for supporting this study provided by the Indonesian Research Center for Veterinary Science (IRCVS) Research Projects Funding in 2017 (Project No: 1806.022.052P). This work was conducted with permission from the Districts Livestock Services staff in Malang and Blitar, East Java Province. Special thanks to Mr. R. Firmansyah and Mr. T. Tarmidi for processing the samples.

\section{REFERENCES}

Aslam, B., N. Kousar, I. Javed, A. Raza, A. Ali, T. Khaliq, F. Muhammad, \& J. A. Khan. 2016. Determination of enrofloxacin residues in commercial broilers using high-performance liquid chromatography. Int. J. Food Prop. 19:24632470. https://doi.org/10.1080/10942912.2015.1027922

BSN (Badan Standardidasi Nasional). 2000. Standar Nasional Indonesia No. 01-6366-2000. Batas maksimum cemaran mikroba dan batas maksimum residu dalam bahan makanan asal hewan. Badan Standarisasi Nasional, Jakarta.

Cañada-Cañada, F., A. Espinosa-Mansilla, A. J. Girón, \& A. M. De La Peña. 2012. Simultaneous determination of the residues of fourteen quinolones and fluoroquinolones in fish samples using liquid chromatography with photometric 
and fluorescence detection. Czech J. Food Sci. 30:74-82. https://doi.org/10.17221/12/2010-CJFS

EC (European Commission). 2002. European Commission: Implementing Council Directive 96/23/EC concerning the performance of analytical methods and the interpretation of results. https://op.europa.eu/en/publication-detail/-/ publication/ed928116-a955-4a84-b10a-cf7a82bad858/ language-en.

EMEA. 1998. Enrofloxacin (Modification for bovine, porcine, and poultry). https://www.ema.europa.eu/en/documents/ mrl-report/enrofloxacin-modification-bovine-porcinepoultry-summary-report-2-committee-veterinary-medicinal_en.pdf. [13 October 2020].

Er, B., F. Kaynak Onurdă, B. Demirhan, S. Özgen Özgacar, A. Bayhan Öktem, \& U. Abbasoğlu. 2013. Screening of quinolone antibiotic residues in chicken meat and beef sold in the markets of Ankara, Turkey. Poult. Sci. 92:2212-2215. https://doi.org/10.3382/ps.2013-03072

Gouvêa, R., F. F. Dos Santos, M. De Aquino, \& V. L. Pereira. 2015. Fluoroquinolones in industrial poultry production, bacterial resistance and food residues: A review. Rev. Bras. Cienc. Avic. 17:1-10. https://doi.org/10.1590/1516-635x17011-10

Hanna, N., P. Sun, Q. Sun, X. Li, X. Yang, X. Ji, H. Zou, J. Ottoson, L. E. Nilsson, \& B. Berglund. 2018. Presence of antibiotic residues in various environmental compartments of Shandong province in eastern China: Its potential for resistance development and ecological and human risk. J. Environ. Int. 114:131-142. https://doi.org/10.1016/j. envint.2018.02.003

Hasanen, F., M. Mohammed, H. M. Hassan, \& F. Amro. 2016. Ciprofloxacin residues in chicken and turkey carcasses. Benha. Vet. Med. J. 31:136-143. https://doi.org/10.21608/ bvmj.2016.31282

Lee, H. J., S. H. Cho, D. Shin, \& H. S. Kang. 2018. Prevalence of antibiotic residues and antibiotic resistance in isolates of chicken meat in Korea. Korean J. Food. Sci. Anim. Resour. 38:1055-1063. https://doi.org/10.5851/kosfa.2018.e39

Marni, S., A. M. Mustafa, \& M. R. Marzura. 2011. Analysis of quinolones in poultry muscles using liquid chromatography-tandem mass spectrometry. Malaysian J. Vet. Res. 2:1-5.

Mashak, Z., A. Mojaddarlangroodi, T. Mehdizadeh, \& A. E. Fathabad. 2017. Detection of quinolones residues in beef and chicken meat in hypermarkets of urmia, Iran using ELISA. Iran Agric. Res. 36:73-77.

Moudgil, P., J. S. Bedi, R. S. Aulakh, \& J. P. S. Gill. 2019. Analysis of antibiotic residues in raw and commercial milk in Punjab, India vis-à-vis human health risk assessment. J. Food Saf. 39:1-8. https://doi.org/10.1111/jfs.12643

Ovando, H. G., N. Gorla, A. Weyers, L. Ugnia, \& A. Magnoli. 2004. Simultaneous quantification of ciprofloxacin, enrofloxacin and balofloxacin in broiler chicken muscle. Arch. Med. Vet. 36:93-98. https://doi.org/10.4067/ S0301-732X2004000100011

Oyedeji, A.O., T. A. M. Msagati, A. B. Williams, \& N. U. Benson. 2019. Determination of antibiotic residues in frozen poultry by a solid-phase dispersion method using liquid chromatography-triple quadrupole mass spectrometry. Toxicol. Rep. 6:951-956. https://doi.org/10.1016/j. toxrep.2019.09.005

Pena, A., L. J. G. Silva, A. Pereira, L. Meisel, \& C. M. Lino. 2010. Determination of fluoroquinolone residues in poultry muscle in Portugal. Anal. Bioanal. Chem. 397:2615-2621. https://doi.org/10.1007/s00216-010-3819-0

Pereira, A. M. P. T., L. J. G. Silva, J. Rodrigues, C. Lino, \& A. Pena. 2018. Risk assessment of fluoroquinolones from poultry muscle consumption: Comparing healthy adult and pre-school populations. Food Chem. Toxicol. 118:340347. https://doi.org/10.1016/j.fct.2018.05.035

Pugajeva, I., J. Avsejenko, E. Judjallo, A. Bērziņš, E. Bartkiene, \& V. Bartkevics. 2018. High occurrence rates of enrofloxacin and ciprofloxacin residues in retail poultry meat revealed by an ultra-sensitive mass-spectrometric method, and antimicrobial resistance to fluoroquinolones in Campylobacter spp. Food Addit. Contam - Part A. Chem. Anal. Control Expo Risk Assess. 35:1107-1115. https://doi. org/10.1080/19440049.2018.1432900

San Martin, B., J. Cornejo, L. Lapierre, D. IragÜen, F. Pérez, H. Hidalgo H, \& F. Andre. 2010. Withdrawal time of four pharmaceutical formulations of enrofloxacin in poultry according to different maximum residues limits. J. Vet. Pharmacol. Ther. 33:246-251. https://doi. org/10.1111/j.1365-2885.2009.01127.x

Šandor, K., T. Svjetlana, M. Andrišic, I. Žarkovic, \& P. Eleonora. 2012. In-use stability of enrofloxacin solution for injection in multi-dose containers. Acta. Vet. Brno. 62:213225. https://doi.org/10.2298/AVB1203213S

Siswanto. 2014. Studi Diet Total: Survei Konsumsi Makanan Individu Indonesia 2014. Lembaga Penerbitan Badan Penelitian dan Pengembangan Kesehatan, Kementerian Kesehatan RI, Jakarta.

Sultan, I. A. 2014. Detection of enrofloxacin residue in livers of livestock animals obtained from a slaughterhouse in Mosul City. J. Vet. Sci. Technol. 5:2-4.

Sureshkumar, V. \& G. Sarathchandra. 2018. Prevalence of enrofloxacin and its primary metabolite ciprofloxacin residues in broiler meat and organ samples of field origin. Glob. J. Bio-Sci. Biotech. 7:324-326.

Thi Huong-Anh, N., D. Van Chinh, \& T. Thi Tuyet-Hanh. 2020. Antibiotic residues in chickens and farmers' knowledge of their use in Tay Ninh Province, Vietnam, in 2017. Asia-Pac. J. Pub. Health. 32:126-132. https://doi. org/10.1177/1010539520909942

Trouchon, T. \& S. Lefebvre. 2016. A review of enrofloxacin for veterinary use. Open J. Vet .Med. 6:40-58. https://doi. org/10.4236/ojvm.2016.62006

Tsai, M. Y., C. F. Lin, W. C. Yang, C. T. Lin, K. H. Hung, \& G. R. Chang. 2019. Health risk assessment of banned veterinary drugs and quinolone residues in shrimp through liquid chromatography-tandem mass spectrometry. Appl. Sci. 9:1-11. https://doi.org/10.3390/app9122463

Vishnuraj, M. R., G. Kandeepan, K. H. Rao, S. Chand, \& V. Kumbhar. 2016. Occurrence, public health hazards and detection methods of antibiotic residues in foods of animal origin: A comprehensive review. Cogent Food Agric. 2:1235458. https://doi.org/10.1080/23311932.2016.1235458

Yamaguchi, T., M. Okihashi, K. Harada, Y. Konishi, K. Uchida, M. H. N. Do. H. D. T. Bui, T. D. Nguyen, P. D. Nguyen, \& V. V. Chan. 2015. Antibiotic residue monitoring results for pork, chicken, and beef samples in Vietnam in 2012-2013. J. Agric Food Chem. 63:5141-5145. https://doi.org/10.1021/ jf505254y 